Dossiê

\title{
A Sociologia da Infância portuguesa e o seu contributo para 0 campo dos estudos sociais da infância
}

Manuel Jacinto Sarmento ${ }^{1}$

Resumo: A Sociologia da Infância em Portugal desenvolveu-se, há cerca de vinte anos, por autonomização da investigação face às sociologias da educação, da comunicação e da família, através da definição de um objeto próprio: as crianças, enquanto seres sociais, e a infância, enquanto categoria social de tipo geracional. Desde cedo procurou estabelecer o diálogo com as sociologias da infância de expressão anglófona e francófona e estabeleceu sólidos vínculos com a investigação multidisciplinar da infância nos países de expressão portuguesa, e, em especial, no Brasil. A forte vinculação com as realidades das crianças portuguesas tem vindo a contribuir para que a sociologia da infância esteja aberta aos processos de pluralização da construção social da infância, à crítica aos processos de opressão das crianças e às consequências das desigualdades sociais na infância, e à assunção de uma dimensão de intervenção social e política transformadora das condições de vida das crianças.

Palavras-chave: Sociologia da Infância; Normatividade; Sociologia crítica.

THE PORTUGUESE SOCIOLOGY OF CHILDHOOD AND ITS CONTRIBUTION TO THE INTERNATIONAL FIELD OF SOCIAL STUDIES OF CHILDHOOD

1 Instituto de Educação e Centro de Estudos da Criança (CIEC) da Universidade do Minho - Braga Portugal - sarmento@ie.uminho.pt 
Abstract: The Sociology of Childhood in Portugal is developed, twenty years ago, by the autonomization of research from sociology of education, sociology of media and sociology the family. It is constituted by the adoption of an object of its own: children, as social beings, and childhood, as a social category of generational type. From its begin, it sought to establish a dialogue with English-speaking and Francophone-speaking childhood sociologies and established strong links with multidisciplinary childhood research in Portuguese-speaking countries, especially in Brazil. The strong connection with the realities of Portuguese childhood has contributed to the Portuguese sociology of childhood research the processes of pluralization of childhood normativity, to criticism of the processes of oppression of children and to the consequences of social inequalities in childhood. The Portuguese sociology of childhood is embedded on social intervention and political transformation of the living conditions of children.

\section{Keywords: Sociology of Childhood; Normativity; Critical Sociology.}

\section{Introduç̃̃o}

O campo científico da Sociologia da Infância em Portugal é relativamente recente. A criação na Universidade do Minho, em 1997, do projeto de investigação sobre a infância em Portugal (PIIP), numa matriz claramente interdisciplinar, mas que incorporava os contributos da Sociologia da Infância, então em fase de plena afirmação na Europa, poderá ser considerado como o primeiro momento de afirmação da disciplina no país. Na sua sequência, foram criados cursos de formação pós-graduada (mestrado e doutoramento) em Sociologia da Infância e a disciplina desenvolveu-se em algumas universidades do país, tendo sido simultaneamente garantida a presença de investigadores portugueses nos comitês de pesquisa das principais associações científicas de sociologia na Europa e no mundo².

Neste texto, procuramos enunciar o contributo específico da Sociologia da Infância que se pratica em Portugal para o desenvolvimento do campo dos estudos sociais da infância. Com efeito, mais importante do que dar conta do percurso da disciplina científica no contexto institucional da produção sociológica em Portugal, é assinalar como a infância é tematizada e o sentido do trabalho teórico na compreensão dos modos como se estruturam as relações geracionais

2 É o caso da European Sociological Association (ESA), da International Sociological Association (ISA) e da Association Internationale de Sociologues de Langue Française (AISLF). 
e quais são os contributos teóricos e empíricos para interpretar as condições sociais e as práticas sociais das crianças.

A produção sociológica da infância em Portugal procurou sempre romper com as fronteiras que a confinassem ao domínio da "ciência sociológica normal”, buscando, desde sempre, estabelecer relações com outros domínios do conhecimento relevantes para o conhecimento acerca das crianças, nomeadamente as ciências da educação, as ciências da comunicação, a psicologia (especialmente a psicologia cultural e a psicologia social), a antropologia, as ciências jurídicas e, no campo sociológico, as sociologias da educação, das desigualdades e da família. Do mesmo modo, sempre evitou o confinamento a uma concepção autocentrada no seu universo linguístico ou cultural, procurando estabelecer vínculos com vários espaços de produção linguística. Sirota (2012) reconhece a vocação de articulação da Sociologia da Infância portuguesa entre campos referenciais comumente desencontrados, como são os da sociologia de expressão anglófona vis-a-vis a de expressão francófona - bem como promovendo estudos comparativos entre crianças de vários países, sobretudo de expressão oficial portuguesa.

É provável, pelo que acima se disse, que a Sociologia da Infância que se pratica em Portugal contribua para o debate de questões sociológicas que são transversais aos países, às traduções culturais, aos universos linguísticos e aos fatores institucionais que estruturam os campos científicos, tendo uma vocação eminentemente universalista. Fá-lo, porém, a partir das suas próprias condições de produção científica e investiga prioritariamente as condições estruturais e as práticas sociais das crianças portuguesas, com as suas particularidades.

Portugal é um país do sul da Europa, distante dos indicadores de rendimento per capita dos países do centro e do norte europeus, passou recentemente por um período de crise econômica e financeira, com uma gestão draconiana realizada sob a égide de organizações reguladoras internacionais (nomeadamente o FMI, a União Europeia e o Banco Central Europeu) que levou ao aumento das desigualdades sociais e ao empobrecimento de classes populares e amplos setores da classe média, e possui um Estado Social recente, que emergiu da revolução democrática de 25 de abril de 1974 e que sofre as vicissitudes decorrentes das influências de políticas austeritárias e da pulsão neoliberal de vários governos. Assim, as crianças portuguesas estão numa situação de especial vulnerabilidade, apesar dos progressos importantes que se verificaram com a democracia nas condições de bem-estar infantil (Portugal tem praticamente a totalidade da sua população entre os 3 e os 18 anos frequentando a educação, tem uma cobertura 
alargada de saúde pública infantil e é um dos países do mundo com mais baixas taxas de mortalidade infantil). Esse fato tem um importante impacto na investigação sociológica da infância, que encontra nos direitos da criança, na sua conceituação e, sobretudo, nas suas condições de concretização, um importante tópico de análise.

Neste texto, procuraremos identificar, numa primeira parte, as principais problemáticas da Sociologia da Infância praticada em Portugal e, numa fase posterior, identificaremos os contributos principais da investigação acumulada para a construção da disciplina, a saber: o debate sobre a temática da normatividade infantil e a pluralidade das condições de generatividade, especialmente em crianças de grupos sociais em situação de subalternidade; a configuração de uma orientação paradigmática sustentada na teoria crítica, num campo internacionalmente marcado pela predominância de outras abordagens, nomeadamente estruturalistas, interpretativas ou desconstrucionistas; a sociologia pública como importante vertente da produção e disseminação do conhecimento.

Esses contributos não estão presentes em toda a literatura sociológica da infância produzida em Portugal nem totalizam as tendências, correntes e abordagens teóricas e metodológicas, mas, por sua importância e relativa singularidade, constituem aspectos que queremos especialmente destacar, enquanto síntese do que pode ser a marca de uma prática sociológica num campo que ganhou autonomia, visibilidade e significado, mas está longe, no plano interno e externo, de possuir a notoriedade de outros domínios das Ciências Sociais.

\section{As "figuras da infância"}

Em um texto recente, procedemos a uma revisão da produção de duas décadas de trabalhos em Sociologia da Infância em Portugal, procurando descortinar o modo como os constructos sobre a infância são produzidos a partir do estudo das realidades empíricas perspectivadas pelas matrizes teóricas da Sociologia (Sarmento; Fernandes; Tomás, 2017). Tomando de empréstimo o conceito de "figura", proposto por Genette (1996-2000) nos seus trabalhos de narratologia estrutural, fomos à procura da ação de estruturação discursiva sobre as crianças e dos seus resultados, cristalizados em formas de significação das crianças, representativas do trabalho de abstração e de síntese sobre as condições estruturais em que vivem e sobre as suas práticas sociais: "figuras de criança são (...) formas de formulação não ficcionais, mas abstratas, fundadas na sistematização do conhecimento produzido pela sociologia que se ocupa da infância enquanto condição social e das crianças como atores sociais concretos" (idem: 43). 
Foram encontradas seis figuras: a criança pública; a criança sujeito ativo de direitos; a criança em risco; a criança do "ofício de criança"; a criança sujeito cultural e a criança cosmopolita.

A figura da criança pública refere-se à análise das caraterísticas da imagem social da criança, tal como ela é veiculada pelos media e se constitui como referente nas percepções e representações coletivas. A imagem pública da criança oscila continuamente entre a esperança e a tragédia (Tomás; Fernandes; Sarmento, 2011). A esperança focaliza-se na criança como projeto de uma vida melhor, um futuro mais risonho, numa população mais qualificada para uma economia mais próspera. A tragédia expressa-se nos múltiplos casos em que a violência contra as crianças se exerceu, criando um sentimento nacional de preocupação e luto: para além do caso muito midiatizado do desaparecimento, até hoje, de Maddie, uma criança britânica que passava férias com os seus pais no sul de Portugal, o assassinato de crianças no interior das famílias fere de sangue os jornais com alguma frequência, para além do caso Casa Pia, ou seja, da denúncia e posterior condenação de várias personalidades da elite associadas à violência sexual e a redes pedófilas constituídas a partir de uma secular casa de acolhimento de crianças administrada pelo Estado. De fato, a visibilidade das crianças em Portugal oscila entre o ideal romântico de uma infância que restaura o sentido da vida coletiva e o pathos da crise social, nas suas manifestações mais trágicas. A exposição das crianças à crise econômica e o aumento da pobreza infantil não fizeram senão aumentar esta situação.

Para além dos estudos dedicados à visibilidade da infância nos media (Ponte, 2005; 2013; Marôpo, 2010), a Sociologia da Infância interroga o sentido da presença da criança ao espaço público, deslindando as complexas articulações entre reserva privada da vida familiar e da guarda das crianças e exposição pública das crianças (Almeida, 2009).

O lugar da criança na sociedade, como não poderia deixar de ser, é amplamente interrogado, originando vários estudos e publicações sobre a infância como construção social e a ordem geracional da infância (Pinto, 1997; Pinto; Sarmento, 1997; Almeida, 2000, 2009; Ferreira, 2000; Sarmento, 2005; Saramago, 2005).

A figura pública da infância convoca a questão da cidadania da infância e da construção política do lugar da criança na sociedade. São de salientar, nesse caso, os estudos realizados sobre a criança em contexto educacional, numa perspectiva que se desprende dos estudos mais enraizados em sociologia da 
educação, para se centrarem na "ordem social das crianças" (Ferreira, 2004) conforme ela se manifesta nos interstícios da ordem institucional da escola e instituições educativas, com destaque para as dimensões participativas das crianças (Sarmento; Abrunhosa; Fernandes, 2005), bem como a interrogação sobre o lugar da criança na cidade, no âmbito das políticas urbanas e das possibilidades de participação social das crianças (Trevisan, 2014; Sarmento; Fernandes; Tomás, 2009). Mas aí, estamos já perante outra figura de criança.

A figura da criança como sujeito de direitos tem expressão em pesquisas que interrogam o lugar da criança na configuração da ordem jurídica, com destaque especial para as confluências e contradições entre direitos de participação, provisão e de participação (Fernandes, 2009; Tomás, 2012), ou na avaliação internacional do estado de aplicação dos direitos da criança (Tomás; Fernandes, 2012; Araújo; Fernandes, 2016). Essa figura é transversal a todas as outras e emerge em estudos que têm por referente, todavia, outras dimensões analíticas e estão associadas mais fortemente a outras imagens sociais da infância.

É o caso, nomeadamente, da figura da "criança em risco". O conceito de "risco" é usado com frequência de modo acrítico, dado que se descontextualiza da situação ou do sujeito que se encontra vulnerabilizado das condições estruturais que o colocam nessa posição. "Criança em risco" e "família em risco" são expressões do senso comum que ontologizam a situação social específica em que a criança se encontra, escamoteando as condições estruturais e promovendo, com frequência, a atribuição de responsabilidade causal ao próprio sujeito da situação de vulnerabilidade em que se encontra, num processo de acusação da vítima. O conceito de risco necessita, por isso, de ser desconstruído, sinalizando a sua gênese nas desigualdades sociais e na ruptura entre os processos de ideologização do contrato social da modernidade e as condições de fato da sua atualização na modernidade tardia, de dominação do capital financeiro globalizado (Beck, 1992). A utilização na Sociologia da Infância em Portugal da figura da criança de risco tem, usualmente, um sentido analítico e supõe a desconstrução dos efeitos perversos que o seu uso acarreta. Para tanto, é indispensável a análise macroestrutural do que afeta as crianças e as priva de direitos, conduzindo a uma vulnerabilização e precarização das suas condições de existência. Essa análise é particularmente relevante no que diz respeito ao estudo da pobreza infantil e das condições econômicas e sociais que a produz, bem como das políticas públicas que estão associadas à sua intensificação. Os anos da crise econômica e financeira originaram um número considerável de importantes trabalhos que analisam a pobreza infantil em Portugal (Bastos; Nunes, 2009; Sarmento; Veiga, 2010; Wall et al., 2014a, 2014b; Sarmento; Fernandes; Trevisan, 
2014, 2015; Samagaio, 2017; Diogo, 2018) sendo que alguns dos trabalhos estão especialmente atentos às formas de resposta das crianças face a situações de pobreza e exclusão social (Wall et al., 2014a; Sarmento; Trevisan, 2017).

Um outro tema constitutivo dessa figura é o do atendimento de crianças e instituições de acolhimento residencial, tema que tem conduzido a uma significativa quantidade de teses e de dissertações, considerando o elevado número relativo de crianças internadas em acolhimento residencial. A análise sociológica desses aspectos não dispensa a discussão das políticas públicas e introduz como importante elemento de questionamento as percepções e as representações das crianças em contexto de acolhimento (Fernandes, 2007; Neves, 2008; Carvalho et al., 2013). Também a abordagem da ruptura comportamental das crianças face à norma social constitui uma importante linha de investigação no campo (Carvalho, 2003; 2013).

A figura da criança do "ofício de criança" tem também uma importância acentuada na investigação da Sociologia da Infância em Portugal. O conceito de "ofício de criança" emerge por influência direta da Sociologia da Infância francófona, (especialmente a partir das obras de Chamboredon; Prévot, 1982; Sirota, 1993; Perrenoud, 1995) e refere-se especialmente às atividades ocupacionais das crianças em contexto educativo.

Portugal esteve sob o crivo da crítica internacional, nos anos 80 do século passado, por apresentar um número significativo de crianças trabalhadoras, por comparação com o resto da Europa. Nessa sequência, foram desencadeados vários programas centrados na erradicação do trabalho infantil. Em articulação com essa realidade social, o conceito de ofício de criança ganhou uma espessura própria, por considerar a dimensão do trabalho económico direto, acepção esta não presente no conceito inicial de "métier d'enfant". Nesse sentido, a tematização de ofício de criança na pluralidade das suas dimensões - na ordem educacional, familiar e produtiva - exprime-se num conjunto de investigações centradas nas condições de trabalho das crianças, seja num sentido conceitual (Sarmento, 2000; 2015), seja no âmbito do trabalho domiciliar (Sarmento; Bandeira; Dores, 2000), das atividades produtivas em geral (Sarmento et al., 2005), em atividades rurais (Sarmento; Stropasolas, 2010), no trabalho artístico (Melro, 2010; Melro; Tomás, 2015), ou no cruzamento entre trabalho infantil e atividades educativas (Sarmento et al., 1997).

A análise da condição do trabalho escolar como ofício é também objeto da investigação em Sociologia da Infância. A par do estudo de largo fôlego sobre a investigação portuguesa em educação que usa os referenciais infância e criança (Rocha; Ferreira, 2008), desenvolveram-se também estudos que questionam o 
sentido atual do desempenho do ofício de aluno, em processo de transição e mudança estrutural (Sarmento, 2011) e a interrogação sobre o ofício de criança, numa perspectiva crítica e emancipatória da Educação Infantil (Sarmento, 2013). Esse ponto é fundamental, porque:

Do ponto de vista epistemológico e sociológico, criança e aluno são objetos diferentes e a separação analítica desses dois ofícios é talvez uma das dimensões principais do surgimento e posterior desenvolvimento da sociologia da infância em Portugal. Reside aqui a novidade que os textos trazem para a análise do panorama nacional: a discussão entre os dois ofícios ao contestar a existência da criança somente enquanto "aluno/a" e a unidimensionalidade e dicotomia entre ofícios. A defesa da conceção da criança consignada a um lugar social, o da infância, na suas múltiplas realidades e dimensões contrapõe a visão dominante e assume-se como um pressuposto consensual entre os/as sociólogos/as da infância em Portugal" (Sarmento; Fernandes; Tomás, 2017)

As relações entre cultura escolar e culturas da infância são cruciais na distinção analítica entre os ofícios de criança e de aluno. A figura da criança sujeito de cultura assenta no conceito de culturas da infância como processos estruturados de produção simbólica realizados pelas crianças, a partir das suas interações intra e intergeracionais e expressos nos jogos, brincadeiras, formas de expressão, rituais, cerimônias e demais processos pelos quais as crianças criam e atribuem significação ao mundo. A partir de referenciais teóricos consolidados na abordagem socioantropológica das culturas infantis (especialmente dos estudos de Hardman, 2001[1973]; Corsaro, 1997; Corsaro; Eder, 1990; Fernandes, 2004; Delalande, 2001), estas são estudadas assumindo as crianças como sujeitos de culturas, produtores das suas próprias interpretações e configuradores de redes de significado estruturados e de transmissão intrageracional continuada (Sarmento, 2003; 2004; 2007).

Contrariando a ideia do senso comum de que as crianças são espectadoras passivas da produção televisiva, Pinto (2000) demonstra, por meio de um trabalho empírico de grande fôlego, como as crianças interpretam e adequam no quotidiano os programas televisivos, apresentando com frequência pontos de vista críticos sobre o que observam.

Também sobre o jogo e as práticas lúdicas, várias investigações assinalam a criatividade e inventividade infantil, em contextos multiculturais múltiplos, mesmo se a indústria cultural ameaça poderosamente as práticas brincantes 
(Silva, 2011; Colonna, 2012; Barra, 2016). Em especial, estudos sobre as crianças e a Internet (Almeida; Delicado; Alves, 2008; Almeida, 2015) procuram discernir os modos de ação e interpretação das crianças, na configuração dos seus quotidianos, em que a Web e as tecnologias de informação e comunicação se apresentam como interlocutores materiais ou actantes na sua própria produção cultural.

A globalização cultural, por efeito da indústria cultural e da Web, é um traço impressivo da modernidade da infância. Mas não é esse o único traço. A imagem da criança cosmopolita procura dar conta de um dos efeitos e consequências da globalização da infância, nomeadamente o que se articula com a realização de práticas contra-hegemônicas de efeitos globais, nomeadamente através da intervenção em nome dos direitos da criança. A atual vaga migratória, em que milhares de crianças morrem afogadas no mediterrâneo, por efeito da ação conjugada das precárias condições de luta pela sobrevivência face à guerra infinita que assola os seus países e as barreiras colocadas por alguns países europeus, atribui à defesa de uma concepção de criança cosmopolita, cidadã do mundo e detentora de direitos transnacionais uma atualidade que a Sociologia da Infância ainda não conseguiu cobrir plenamente. A definição do conceito de cosmopolitismo infantil (Tomás, 2011; Tomás; Fernandes, 2004), porém, assinala um caminho de pesquisa, cuja construção teórica encontra boas balizas para ser prosseguido.

Se as figuras da infância permitem sistematizar a produção científica portuguesa em Sociologia da Infância ${ }^{3}$ é, porventura, nos debates teóricos que melhor se poderão encontrar os aspectos de maior aporte da investigação em Sociologia da Infância no país.

\section{Debates teóricos}

A especificidade da Sociologia da Infância produzida em Portugal pode ser melhor compreendida se considerarmos os debates teóricos que tem promovido e que desenham um mapa de tendências configuradoras de um espaço teórico e metodológico próprio. Analisaremos três desses debates, numa seleção que é necessariamente decorrente de um ponto de vista particular sobre o campo. Outros olhares poderiam, porventura, sinalizar outros debates e perspectivas. Essa seleção é feita a partir de um olhar interno, implicado e, por isso, necessariamente parcial. Referir-nos-emos às questões da normatividade da infância, à concepção crítica da sociologia, à prática de sociologia pública.

3 A síntese realizada não totaliza o conjunto de trabalhos produzidos. Apenas trouxemos os que se nos afiguram mais significativos. Remetemos para o texto onde esse esforço de compilação é realizado (Sarmento; Fernandes; Tomás, 2017). 


\section{A normatividade}

A diferença entre as gerações e as suas condições de existência é um processo largamente estudado na sociologia da infância e é mesmo estruturante do seu percurso teórico (e.g. Qvortrup, 2009). As gerações distinguem-se umas das outras e a sua diferenciação é constitutiva de cada uma delas. Elas são socialmente construídas, a partir da criação de normas sociais que estabelecem as respectivas relações e que garantem o que é aceitável, admissível e adequado, ou, inversamente, o que é ilegítimo, interdito ou considerado impróprio. Por exemplo, nas sociedades modernas de matriz ocidental e europeia é considerado inadequado que as gerações idosas tenham uma atividade produtiva regular e, em contrapartida, o "direito ao trabalho" da população adulta é considerado como uma norma social (apesar da sua denegação se manifestar no relativamente elevado desemprego existente e nos países capitalistas ocidentais).

A mútua produção das gerações ou "generatividade" (Honig, 2009) é profundamente normativa. É desse modo que se define o que é ser criança e o que lhe é impróprio. O próprio conceito de "infância" é utilizado, por vezes, não no sentido analítico de uma categoria geracional própria, mas como um conceito puramente normativo. É quando se utiliza na expressão corrente de "crianças sem infância", isto é, desprovidas das caraterísticas que normativamente lhe estão associadas: proteção, frequência da escola, pertença familiar, condições mínimas de conforto, acesso e usufruto de atividades lúdicas, etc. A menos que aceitemos que, sem infância, esses seres de pequena idade são "não crianças" como lucidamente assinala Marchi (2007) -, teremos de considerar que essa "norma" de infância não é universal e temos de pluralizar o sentido da normatização infantil.

É aqui que reside o debate sobre normatividade. A condição de especial vulnerabilidade das crianças pobres em Portugal, no Brasil e nos países africanos de língua oficial portuguesa (o diálogo com a pesquisa brasileira e africana, bem como relações acadêmicas com a América Latina, tem sido crucial para este debate) apresenta um elevado número de crianças fora da norma ocidental e eurocêntrica, que vivem fora da família (meninos de rua e crianças em situação de acolhimento), abandonam precocemente a escola e são trabalhadores infantis, não são salvaguardados por políticas de Estado de proteção social, integram grupos étnicos e culturais distintos, como as crianças ciganas ou as crianças indígenas, etc. A investigação da condição social da infância das crianças excluídas, à margem, em posição de subalternidade não pode ser feita sem o questionamento da norma ocidental da infância. 
O debate sobre normatividade infantil tem-se feito essencialmente a partir de dois caminhos que se cruzam.

O primeiro é o da crítica da posição hegemônica (inclusive, no interior do próprio campo teórico) sobre a universalidade da norma ocidental e eurocêntrica da infância e das suas consequências teóricas e políticas no esbatimento das diferenças culturais e sociais das crianças em situação de subalternidade ou periferia. Essa linha de discussão procura identificar as complexas relações entre identidade geracional e diferença cultural, resgatar da invisibilidade crianças "invisíveis", através de um trabalho de promoção de uma "sociologia das ausências" (Santos, 2003), potenciar uma leitura crítica da Convenção sobre os Direitos da Criança, ressalvando a exigência de uma garantia política que atenda à diferença no combate às desigualdades sociais e promovendo uma visão cosmopolítica da infância (Marchi; Sarmento, 2017; Sarmento; Marchi; Trevisan, 2018; Tomás, 2009).

O segundo caminho é o do levantamento das práticas culturais das crianças a partir de contextos periféricos da hegemonia da cultura global, mobilizando formas de expressão e de conhecimento do mundo pelas crianças que, em larga medida, escapam aos cânones da cultura escolar. Investigações realizadas com crianças africanas (Colonna, 2012; Barra, 2016), estabelecem um sólido diálogo entre a Sociologia da Infância e os estudos pós-coloniais e associam-se a uma corrente crescente, no plano internacional de crítica ao reducionismo da investigação da infância a partir do Mundo minoritário (Europa e América do Norte), rasurando das questões teóricas e metodológicas os desafios colocados pelas crianças do Sul Global (Tisdall; Punch, 2012; Punch, 2016).

A crítica à normatividade hegemônica é uma das mais prometedoras tarefas em curso no trabalho teórico da sociologia da infância.

\section{Sociologia da Infância crítica}

A investigação sobre normatividade infantil decorre de um pensamento crítico, que é adotado por parte significativa da Sociologia da Infância portuguesa, apesar desta ser, à semelhança do que acontece em todo o mundo, pluriparadigmática. A questão da opressão social da infância pelas concepções paternalistas, a par da opressão social de classe, cultural e de gênero, constituem domínios de investigação que corporizam uma orientação de pesquisa direcionada articulada com projetos de emancipação social.

Esse programa de uma Sociologia de Infância crítica é articulado em torno de sete linhas de orientação: i) prioridade analítica às crianças excluídas/ 
furtivas/ausentes, as crianças das margens sociais; ii) desconstrução da reflexividade institucional da infância, em que se cristalizam as concepções normativas, com contínuo descortinamento das relações entre poder e saber; iii) colocação como alvo de crítica do processo hegemônico de globalização e do individualismo institucional e do modo como opera na infância; iv) historização do processo social de construção das relações intergeracionais, em diálogo com a sociologia histórica; v) adoção de uma perspectiva que cruze estrutura e ação, seguindo os mundos sociais e culturais da infância e das suas práticas sociais; vi) abertura para o estudo transcultural dos processos de socialização e recusa de qualquer etnocentrismo cultural, social ou geracional; vii) adoção de uma perspectiva ética e política da pesquisa (Sarmento; Marchi, 2008).

A perspectiva crítica exprime-se frequentemente em metodologias de investigação orientadas para a participação social transformadora (Fernandes; Santana, 2011). A articulação entre investigação-ação, etnografia e metodologias participativas define uma linha de interpretativismo crítico que é coerente com a articulação dialética dos planos da ação com a estrutura social.

A orientação crítica presente na abordagem sociológica projeta-se em domínios de natureza teórica ou social como o conjunto dos estudos da criança (Sarmento, 2015) ou a educação de infância (Tomás, 2017). Mas também se articula com o sentido de uma sociologia de intervenção pública.

\section{Sociologia da Infância pública}

A participação da Sociologia da Infância na avaliação e construção das políticas públicas da infância é muito significativa em Portugal. Sem que a Sociologia da Infância portuguesa, em geral, se reivindique da sociologia pública (Buravoy, 2005; 2008), a verdade é que a ligação com a construção das políticas públicas, seja no plano local, seja no plano nacional, tem estado largamente presente. A participação do trabalho teórico da Sociologia da Infância na avaliação e construção das políticas públicas da infância tem sido constante e ultrapassa, em muito, pela sua importância social, a notoriedade que a disciplina possui no interior da comunidade acadêmica das Ciências Sociais e humanas. Aliás, a natureza socialmente implicada da Sociologia da Infância é, ela própria, objeto de debate no interior do campo (cf. Almeida, 2009; Sarmento, 2013).

Assim, vários domínios das políticas públicas têm sido objeto de estudo por sociólogos da infância, frequentemente convidados para a realização de trabalhos de avaliação por organismos governamentais ou por instituições sociais com grande relevância e influência no país. Entre os estudos de avaliação e 
proposta de políticas para a infância, merecem referência os trabalhos sociologicamente orientados de análise da situação dos maus-tratos infantis (Almeida et. al., 1999), a avaliação do Programa para a Eliminação da Exploração do Trabalho Infantil (Sarmento et al., 2005), a avaliação do programa nacional de proteção das crianças em risco (Torres, 2008), os estudos sobre o sistema de acolhimento residencial em Portugal (Carvalho et al., 2013), bem como as propostas de estratégia para o combate à pobreza infantil (Sarmento; Veiga, 2010). Também os estudos sobre o impacto da crise econômica e social nas crianças portuguesas (Wall et al., 2014a, 2014b), as relações entre infância e internet (Almeida et al., 2015) ou os modelos pedagógicos da educação nas escolas rurais (Sarmento; Oliveira, 2005) financiados, respectivamente, pela UNICEF, pela Fundação Calouste Gulbenkian e pela Fundação Van Leer, têm uma matriz de sociologia da infância.

A Sociologia da Infância pública tem também expressão nas múltiplas oportunidades de acompanhamento de projetos de âmbito local, da prevenção do risco infantil ao acompanhamento das cidades amigas das crianças, da formação de profissionais de educação e do serviço social à supervisão científica de instituições de acolhimento residencial, da construção de políticas municipais de promoção da cidadania da infância à intervenção nos programas de luta contra a pobreza infantil.

A configuração pública é um traço marcante da Sociologia da Infância, não deixando de suscitar o questionamento sobre os níveis éticos e êmicos da produção do conhecimento e sobre os sentidos do trabalho científico na produção de uma modernidade reflexiva (Beck; Giddens; Lash, 1997), aberta a dimensões críticas e plurais de análise, capaz de resgatar a infância, na pluralidade da sua condição, do preconceito, do paternalismo e da opressão.

\section{Conclusão}

Desenvolvida a partir de uma forte preocupação com a situação social da infância e emergida das margens da investigação mainstreem em sociologia da educação, sociologia da comunicação e sociologia da família, a Sociologia da Infância em Portugal há mais de vinte anos vem traçando o seu caminho com autonomia, desenvolvendo investigação, formação avançada e extensão universitária em múltiplos domínios.

Fortemente vinculada à realidade social da infância de um país semiperiférico e às contingências de produção científica numa língua própria, fora dos espaços linguísticos dominantes, a Sociologia da Infância praticada em Portugal 
procurou desde cedo articular-se com os centros de produção sociológica em línguas inglesas e francesa, estabelecendo conexões entre as abordagens e problemáticas específicas de cada um desses universos linguísticos. A articulação mais recente com a sociologia de expressão castelhana permitiu completar uma vocação universalista da Sociologia da Infância praticada em Portugal. A expressão na sua própria língua permitiu, desde cedo, o estabelecimento de sólidos laços relacionais com os países de expressão oficial portuguesa, especialmente com o Brasil, e, mais recentemente, com os países africanos que emergiram após o processo de descolonização. Essas relações exprimem-se em projetos de pesquisa comuns, em múltiplas oportunidades de intercâmbio e na formação avançada, de doutoramento e pós-doutoramento, de investigadores brasileiros e africanos em Portugal.

Essa dupla articulação - com a Sociologia da Infância dos países centrais e com as realidades sociais e acadêmicas do Brasil e dos países africanos de expressão oficial portuguesa - constitui um vetor determinante da especificidade da produção científica da Sociologia da Infância que se pratica em Portugal.

Essa especificidade exprime-se no centramento prioritário da investigação nas crianças em situação de exclusão social, afastadas do Estado de bem-estar e em posição de subalternidade face às classes dominantes, comparativamente, às crianças dos setores mais favorecidos das sociedades centrais. Um dos efeitos mais importantes desse centramento, a par da forte veiculação à realidade dos países saídos da colonização portuguesa, consiste na indagação teórica sobre as condições de opressão histórica e atual das crianças das classes populares e dos grupos étnicos colocados em situação de subalternidade.

A temática da igualdade social, seja entre crianças seja numa perspectiva transversal à sociedade, par a par com o estudo e relevação das diferenças, conduziu a Sociologia da Infância à priorização dos direitos da criança, numa perspectiva crítica, como um dos eixos teóricos de interrogação da condição social da infância. A passagem para o questionamento da construção social das relações entre gerações e a produção da normatividade infantil, numa perspectiva de pluralidade e numa visão do conflito social acerca do que é ser criança e do lugar social que lhe é atribuído, é decorrente dessa profunda preocupação com as desigualdades sociais e as diferenças entre crianças.

Complementarmente, a assunção de uma perspectiva crítica é decorrente do reconhecimento social da necessidade de transformação das realidades sociais da infância e de desconstrução analítica das concepções teóricas que naturalizam e reificam essa situação profundamente desigualitária. Não é por isso de estranhar que uma parte importante da Sociologia da Infância portuguesa 
se concretize como sociologia pública, através da intervenção teórica na fundamentação e avaliação de políticas públicas da infância.

Nesse domínio, a Sociologia da Infância portuguesa, articuladora de perspectivas, abordagens e temáticas pelo trabalho de tradução linguística entre universos teóricos de diferentes tradições, concretiza-se como contraponto às tendências uniformizadoras da globalização acadêmica que tendem a ignorar a problematicidade da imposição da norma única de infância ocidentalocêntrica (Sarmento; Marchi; Trevisan, 2018).

Articulação e contraponto teórico: esta é uma boa definição de um campo teórico com vinte anos de existência, mas com um longo caminho ainda a percorrer.

\section{Referências}

ALMEIDA, Ana Nunes de. Olhares sobre a infância: pistas para a mudança. In: Vários, Mundos Sociais e Culturais da Infância. Braga, Instituto de Estudos da Criança da Universidade do Minho, pp. 7-18, 2000.

Para uma Sociologia da Infância. Lisboa: ICS, 2009.

. (Coord.) Infâncias Digitais. Lisboa. Fundação Calouste Gulbenkian, 2015.

ALMEIDA, Ana Nunes de et al. Famílias e maus tratos às crianças em Portugal: relatório final. Lisboa. ICS/CEJ, 1999.

ALMEIDA, Ana Nunes de; DELICADO, Ana; ALVES, Nuno de Almeida. As crianças e a internet: relatório de um inquérito. Lisboa: ICS/FCG, 2008.

ARAÚJO, S. C.; FERNANDES, Natália. A criança como sujeito de direitos no contexto da União Europeia: nuances e diálogos necessários entre os direitos de participação e os direitos de proteção. In: BASTOS, Amália; VEIGA, F. (Eds.). A Análise do bem-estar das crianças e jovens e os direitos da criança. V. N. Famalicão: Edições Húmus, pp. 109-130, 2006.

BARRA, M. Infância e Internet: Interacções na Rede. Azeitão: Autonomia27, 2004. . A Infância na Latitude Zero - As brincadeiras da 'criança global' africana. Tese de Doutoramento em Estudos da Criança. Braga: Universidade do Minho, 2016.

BASTOS, Amélia; NUNES, Francisco. Child poverty in Portugal. Dimensions and dynamics. Childhood, v. 16, n. 1, pp. 67-87, 2009. DOI: 10.1177/0907568208101691

BECK, ULRICH. Risk society: towards a new modernity. London. Sage, 1992.

BECK, Ulrich; GIDDENS, Anthony; LASH, Scott. Reflexive modernization: politics tradition and aesthetics in the modern social order. Cambridge. Polity Press, 1997.

BUCKINGHAM, David. After the Death of Childhood. Growing up in the age of electronic media. Cambridge. Polity Press, 2000. 
BURAWOY, Michael. Por uma sociologia pública. In: BRAGA, Ruy; BURAWOY, Michael. (Eds.). Por uma Sociologia Pública. São Paulo: Alameda, 2008. . For Public Sociology. American Sociologist, v. 70, n. 1, pp. 4-28, 2005.

CARVALHO, Maria João Leote. Entre as Malhas do Desvio. Jovens, Espaços, Trajectórias e Delinquências. Oeiras: Celta, 2003.

. Do Outro Lado da Cidade. Crianças, Urbanização e Violência na Área Metropolitana de Lisboa. Sociologia, Problemas e Práticas, v. 72, pp. 79-101, 2003.

CARVALHO, Maria João Leote. et al. Sistema Nacional de Acolhimento de Crianças e Jovens. Lisboa: FCG, 2013.

CHAMBOREDON, J. C.; PRÉVOT, J. O Ofício de Criança. In: GRÁCIO, Sérgio; STOER, Stephen. Sociologia da Educação II. Antologia - A Construção Social das Práticas Educativas, Lisboa, Livros Horizonte, pp. 51-77, 1982.

COLONNA, Elena. "Eu é que fico com a minha irmâ": vida quotidiana das crianças na periferia de Maputo. Tese de Doutoramento em Estudos da Criança. Braga: Universidade do Minho, 2012.

CORSARO, William Arnold; EDER, Donna. Children's peer cultures. Annual Review of Sociology, v. 16, pp.197-220, 1990. . The Sociology of Childhood. Thousand Oaks. Pine Forge Press, 1997.

DELALANDE, Julie. La Cour de la Récréation. Contribution à une anthropologie de l'enfance. Rennes. Presses Universitaires de Rennes, 2001.

DIOGO, Fernando. A pobreza infantil e o rendimento social de inserção em Portugal: o mesmo problema, tendências distintas. Sociologia, Problemas e Práticas, n. 87, pp. 71-86, 2018. DOI: 10.7458/SPP20188711726.

FERNANDES, Florestan. Folclore e Mudança Social na Cidade de São Paulo. São Paulo, Martins Fontes, 2004.

FERNANDES, Natália. O centro e a margem: Infância, protecção e acolhimento institucional. In: SARMENTO, Manuel Jacinto; VASCONCELLOS, Vera Maria Ramos de (org.), Infância (in)visível. Araraquara: Junqueira \& Marin Editores, pp. 245-275, 2007.

Infância, Direitos e Participação: Representações, Práticas e Poderes. Porto: Afrontamento, 2009.

FERNANDES, Natália; SANTANA, J. P. Pesquisas participativas com crianças em situação de risco e vulnerabilidade: possibilidades e limites. XI Congresso Luso Afro Brasileiro de Ciências Sociais - Diversidades e (Des)igualdades. Salvador, Universidade Federal da Bahia, 2011.

FERREIRA, Maria Manuela Martinho. Salvar os Corpos, Forjar a Razão. Contributo para uma Análise da Criança e da Infância como Construção Social em Portugal. Lisboa. IIE, 2000. 
"A Gente Aqui o que Gosta Mais é de Brincar com os Outros Meninos" - As

Relações Sociais num Jardim da Infância. Porto: Afrontamento, 2004.

GENETTE, Gérard. Figures I -V. Paris: Ed. du Seuil, 1996-2002.

HARDMAN, Charlotte. Can there be an Anthropology of Children? Childhood, v. 8, n. 4, pp. 501-517, 2001.

HONIG, M.-S. How is the Child Constituted in Childhood Studies? In: J. QVORTRUP, Jens; CORSARO, William Arnold; HONIG, M.-S (Eds.), The Palgrave Handbook of Childhood Studies. New York: Palgrave, pp. 62-77, 2009.

MARCHI, Rita de Cassia. Os sentidos (paradoxais) da infância nas ciências sociais: um estudo de sociologia da infância crítica sobre a "não-criança" no Brasil. Tese (Doutorado em Sociologia Política). Universidade Federal de Santa Catarina: Florianópolis, 2007.

MARCHI, Rita de Cassia; SARMENTO, Manuel Jacinto. Infância, Normatividade e Direitos das Crianças: Transições Contemporâneas. Educação e Sociedade. Unicamp, 2017.

MARÔPO, L. S. B. A Mediação na Construção de uma Identidade de Direitos da Infância: Representações Jornalísticas de Crianças e Adolescentes em Portugal e no Brasil (Tese de Doutoramento não publicada). Lisboa: UNL, 2010.

MELRO, A. Actividades das crianças e jovens no espectáculo artístico e desportivo: a infância na indústria do entretenimento. Revista Pedagógica, v. 12, n. 24, pp. 9-29, 2010.

MELRO, A.; TOMÁS, Catarina. Um outro olhar sobre a infância na indústria do entretenimento. In: ARROYO, Miguel Gonzalez; VIELLA, M. A.; SILVA, M. R. (Orgs.), Trabalho Infância. Exercícios tensos de ser criança. Haverá espaço na agenda pedagógica? Petrópolis: Vozes, pp. 215-233, 2015.

NEVES, Tiago. Entre educativo e penitenciário: Etnografia de um centro de internamento de menores delinquentes. Porto: CIIE/Edições Afrontamento, 2008.

PERRENOUD, Philippe. Ofício de Aluno e Sentido do Trabalho Escolar. Porto. Porto Editora, 1995 (trad. port.; ed. original, 1994).

PINTO, Manuel. A Infância como construção social. In: PINTO, Manuel; SARMENTO, Manuel Jacinto. (Orgs.), As Crianças: Contextos e Identidades. Braga. IEC/UM, pp. 31-73, 1997.

. A Televisão no Quotidiano das Crianças. Porto: Afrontamento, 2000.

PINTO, Manuel; SARMENTO, Manuel Jacinto. (Orgs.) As Crianças: Contextos e Identidades. Braga: Centro de Investigação de Estudos da Criança- Universidade do Minho, 1997.

(Orgs.) Saberes Sobre As Crianças: Para um Bibliografia sobre as Crianças e a Infância em Portugal - 1974-1988. Braga. Centro de Estudos da Criança da Universidade do Minho, 1999. 
PONTE, Cristina. Crianças em Notícia. A construção da infância pelo discurso jornalístico. Lisboa: ICS, 2005.

Crianças e Media: Pesquisa Internacional e Contexto Português, do séc. XIX à Atualidade. Lisboa: ICS, 2013.

PUNCH, Samantha. Cross-world and cross-disciplinary dialogue: a more integrated, global approach to childhood studies. Global Studies of Childhood, v. 6, n. 3, pp. 352-364, 2016. DOI: 10.1177/2043610616665033

QVORTRUP, Jens. "The Development in Childhood: Change and Continuity in Generational Relations". In.: QVORTRUP, Jens. (ed.) Structural, Historical and Comparative Perspectives. Social Studies onf Children and Youth, v. 12, pp. 1-26, 2009.

ROCHA, Cristina; FERREIRA, Manuela. As crianças na escola e a reconstituição do seu ofício como alunos/as: Análise da produção académica nacional (1995-2005): Campos disciplinares, instituições e temáticas. Comparências, ausências e prelúdios. Investigar em Educação, v. 6, n. 7, pp. 17-126, 2008.

SAMAGAIO, Florbela. Pobreza e Exclusões - mundos plurais, olhares singulares. Porto. Editora Sílabas e Desafios, 2017.

SANTOS, Boaventura de Souza. Conhecimento Prudente para uma Vida Decente. Porto: Edições Afrontamento, 2003.

SARAMAGO, Sílvia Sara Souza. O Protagonismo das Crianças. (Tese de Doutoramento não publicada). Lisboa: ISCTE, 2005.

SARMENTO, Manuel Jacinto. Os Ofícios da Criança. Vários. Os mundos sociais e culturais da infância. Congresso Internacional - Actas vol. II. Braga: IEC/UM, 2000. . Imaginário e Culturas da Infância. Cadernos de Educação, v. 21, pp. 51-69, 2003.

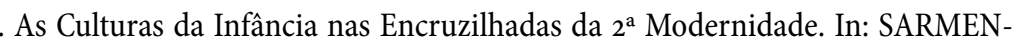
TO, Manuel Jacinto; CERISARA, Ana Beatriz. (Orgs.), Crianças e Miúdos. Perspectivas Sócio-Pedagógicas da Infância e Educação. Porto: Asa, pp. 9-34, 2004.

. Gerações e Alteridade: Interrogações a partir da Sociologia da Infância. Educação \& Sociedade. (Dossiê Temático Sociologia da Infância: Pesquisas com Crianças). CEDES - Brasil, v. 26, n. 91, pp. 361-378, 2005. DOI: http://dx.doi.org/10.159o/ So101-73302005000200003

. Interculturalidade nas Culturas Infantis. In: DORNELAS, L. (Org.), Produzindo Pedagogias Interculturais na Infância. Petrópolis: Vozes, pp. 19-40, 2007.

. A reinvenção do ofício de aluno e de criança. Atos de Pesquisa em Educação, v. 6, n. 3, pp. 581-602, 2011.

A sociologia da infância e a sociedade contemporânea. Desafios conceituais e praxeológicos. In: ENS, Romilda Teodora; GARANHANI, Marynelma Camargo. (Orgs.) Sociologia da Infância e a Formação de Professores. Curitiba: Champagnat, pp. 13-46, 2013. 
"O trabalho das crianças é na escola": debates e controvérsias sobre trabalho infantil e a educação como trabalho. In: ARROYO, Miguel Gonzalez; Viella, M. A.; Silva M. R. (Orgs.), Trabalho Infância. Exercícios tensos de ser criança. Haverá espaço na agenda pedagógica? Petrópolis: Vozes, pp. 55-82, 2015.

. Uma agenda crítica para os Estudos da Criança. Currículo sem Fronteiras, v. 15 , n. 1, pp. 31-49, 2015.

SARMENTO, Manuel Jacinto. (COORD.); TOMÁS, Catarina; MELRO, A.; FERNANDES, P. Avaliação externa do Plano para a Eliminação da exploração do Trabalho Infantil (PEETI) - Dinâmica Institucional e Acção Sócio-Educativa. Relatório Final. Lisboa: PEETI, 2005.

SARMENTO, Manuel Jacinto; ABRUNHOSA, Albertina; FERNANDES, Natália. Participação Infantil na Organização Escolar. Administração Educacional, n. 5, pp. 73-88, 2005.

SARMENTO, Manuel Jacinto; BANDEIRA, A.; DORES, R. Trabalho domiciliário infantil: um estudo de caso no Vale do Ave. Lisboa: MTS, 2000.

SARMENTO, Manuel Jacinto; FERNANDES, Natália; TOMÁS, Catarina. Figuras da criança na sociologia da infância em Portugal. Sociedad e Infancias, n. 1, pp. 39-59, 2017. DOI: $10.5209 /$ SOCI.56363

Políticas Públicas e Participação infantil, Educação, Sociedade e Culturas, no 25, pp. 183-206, 2007.

SARMENTO, Manuel Jacinto; FERNANDES, Natália; TREVISAN, Gabriela. The economic crisis and children's rights to non-discrimination. Teacher Education, v. 22, n. 1, pp. 38-55, 2014.

A redefinição das condições estruturais da infância e a crise económica em Portugal. In: DIOGO, Fernando; CASTRO, Alexandra; PERISTA, Pedro. (Orgs.), Pobreza e exclusão social em Portugal. V. N. Famalicão: Húmus, pp. 81-101, 2015.

SARMENTO, Manuel Jacinto; MARCHI, Rita de Cassia; TREVISAN, Gabriela. "Beyond the modern norm of childhood: children as the margins as a challenge for the sociology of childhood." In: BARALDI, Claudio; COCKBURN, Tom (ed.), Theorizing Childhood: citizenship, rights and participation. Milton Keynes: PalgraveMacmillan, pp. 135- 157, 2018.

SARMENTO, Manuel Jacinto; MEIRA, Eduardo; NEIVA, Olívia; RAMOS, Altina; COSTA, A. A Escola e o trabalho em tempos cruzados. In: PINTO, Manuel; SARMENTO, Manuel Jacinto. (Coords.) As crianças: Contextos e identidades. Braga: IEC/UM, pp. 265-293, 1997.

SARMENTO, Manuel Jacinto; MARCHI, Rita de Cassia. Radicalização da infância na segunda modernidade: para uma sociologia da infância crítica. Configurações, v. 4, pp. 91-113, 2008. DOI: 10.400o/configuracoes.498 
SARMENTO, Manuel Jacinto; OLIVEIRA, Joaquim Marques. “A Escola é o Melhor do Povo..." - Relatório de Revisão Institucional do Projecto das Escolas Rurais. Porto. Profedições, 2005.

SARMENTO, Manuel Jacinto; STROPASOLAS, Valmir Luiz. Os sentidos do trabalho Infantil no campo. Travessias - revista de ciências sociais e humanas em língua portuguesa, v. 10, pp. 233-263, 2010.

SARMENTO, Manuel Jacinto; TREVISAN, Gabriela. A crise social desenhada pelas crianças, Educar em Revista, 2017 (no prelo).

SARMENTO, Manuel Jacinto; VEIGA, Fátima. (Eds.) Pobreza Infantil: Realidades, desafios, propostas. V. N. Famalicão: Edições Húmus, 2010.

SILVA, Alberto Nidio Barbosa de Araújo e. Jogos, Brinquedos e Brincadeiras: Trajetos Intergeracionais. Vila Verde: Athaca, 2011.

SIROTA, Régine. L’emergence d'une sociologie de l'enfance: evolution de l'objet, evolutions du regard. Education et Sociétés, v. 2, pp. 9-33, 1998.

. Le Métier d'Élève : d'une sociologie de la scolarisation à une sociologie de la socialisation Revue Française de Pédagogie, v. 104, pp. 85-108, 1993.

. L'enfance au regard des Sciences sociales. AnthropoChildren, v. 1, pp. 1-20, 2012.

TISDALL, K. M.; PUNCH, Samantha. Not so "new"? Looking critically at childhood studies. Children's Geographies, v. 10, n. 3, pp. 249-264, 2012. DOI: http://dx.doi. org/10.1080/14733285.2016.1219022

TOMÁS, Catarina. Há muitos mundos no mundo. Cosmopolitismo, Participação e Direitos da criança. Porto: Afrontamento, 2011.

. Direitos da criança na sociedade portuguesa: qual o lugar da criança? Da Investigação às Práticas, v. 2, n. 1, pp. 118-129, 2012.

. Para além de uma visão dominante sobre as crianças pequenas: gramáticas críticas na Educação de Infância. Humanidades \& Inovação, v. 4, n. 1, pp. 13-20, 2017. TOMÁS, Catarina; FERNANDES, Natália. O cosmopolistimo infantil: uma causa (sociológica) justa. APS (Org.), Sociedades Contemporâneas: Reflexividade e Acção. Actas do V Congresso Português de Sociologia. Braga: APS, 2004.

. Comments on the reports of the Committee on the rights of the child-Portugal. Barcelona: Huygens, 2012.

TOMÁS, Catarina; FERNANDES, Natália; SARMENTO, Manuel Jacinto. "Jogos de imagens e espelhos: um olhar sobre a infância e as crianças em Portugal”. In: MULLER, V. (org.), Crianças dos Países de Língua Portuguesa: História, culturas e direitos. Maringá, UEM, pp. 189-227, 2011.

TORRES, Anália. (Coord.) Estudo de Diagnóstico e Avaliação das Comissões de Protecção de Crianças e Jovens. Lisboa: CIES-ISCTE, 2008. 
TREVISAN, Gabriela. "Somos as pessoas que temos de escolher, não são as outras pessoas que escolhem por nós”. Infância e cenários de participação pública: uma análise sociológica dos modos de codecisão das crianças na escola e na cidade. (Tese de Doutoramento não publicada). Braga: UM, 2014.

WALL, Karin. et al. As Crianças e a Crise em Portugal: Vozes de Crianças, Políticas Públicas e Indicadores Sociais. Lisboa: UNICEF, 2014.

WALL, Karin; LEITÃO, Mafalda; ATALAIA, Susana. Principais Desenvolvimentos das Políticas de Família em 2013. Lisboa: Observatório das Famílias e das Políticas de Família Instituto de Ciências Sociais da Universidade de Lisboa, 2014.

Recebido em 23/01/2018

Aprovado em 05/06/2018

\section{Como citar este artigo:}

SARMENTO, Manuel Jacinto. A Sociologia da Infância portuguesa e o seu contributo para o campo dos estudos sociais da infância. Contemporânea - Revista de Sociologia da UFSCar, v. 8, n. 2, jul.- dez. 2018, pp. 385-405. 